\title{
The relative contributions of radiative forcing and internal climate variability to the late 20th Century winter drying of the Mediterranean region
}

\author{
Colin Kelley • Mingfang Ting • Richard Seager • \\ Yochanan Kushnir
}

Received: 6 January 2011 / Accepted: 10 October 2011

(C) Springer-Verlag 2011

\begin{abstract}
The roles of anthropogenic climate change and internal climate variability in causing the Mediterranean region's late 20th Century extended winter drying trend are examined using 19 coupled models from the Intergovernmental Panel on Climate Change Fourth Assessment Report. The observed drying was influenced by the robust positive trend in the North Atlantic Oscillation (NAO) from the 1960s to the 1990s. Model simulations and observations are used to assess the probable relative roles of radiative forcing, and internal variability in explaining the circulation trend that drove much of the precipitation change. Using the multimodel ensemble we assess how well the models can produce multidecadal trends of realistic magnitude, and apply signalto-noise maximizing EOF analysis to obtain a best estimate of the models' (mean) sea-level pressure (SLP) and precipitation responses to changes in radiative forcing. The observed SLP and Mediterranean precipitation fields are regressed onto the timeseries associated with the models' externally forced pattern and the implied linear trends in both fields between 1960 and 1999 are calculated. It is concluded that the radiatively forced trends are a small fraction of the total observed trends. Instead it is argued that the robust trends in the observed NAO and Mediterranean rainfall during this period were largely due to multidecadal internal variability with a small contribution from the external forcing. Differences between the observed and NAO-associated precipitation trends are consistent with those expected as a response to radiative forcing. The radiatively forced trends in circulation
\end{abstract}

Lamont-Doherty Earth Observatory Contribution Number 7504.

C. Kelley $(\bowtie) \cdot$ M. Ting · R. Seager · Y. Kushnir

Columbia University's Lamont-Doherty Earth Observatory,

61 Route 9 W, Palisades, NY 10964, USA

e-mail: ckelley@ldeo.columbia.edu and precipitation are expected to strengthen in the current century and this study highlights the importance of their contribution to future precipitation changes in the region.

Keywords Mediterranean - Drying - Radiative forcing · Hydroclimate · Winter

\section{Introduction}

The Mediterranean region experienced a widespread downward trend in wintertime precipitation over the latter half of the 20th century (Hurrell 1995; Hurrell et al. 2003). This observed winter drying trend, particularly from the 1960s to the 1990s (Fig. 1), was accompanied by a strong positive linear trend in the extended winter North Atlantic Oscillation (NAO). Because the linear trend in the winter NAO from the 1960 s to the 1990 s was the strongest 30 -year trend observed during the 20th Century, it led to considerable debate as to the mechanisms responsible. Did external radiative forcing in the form of rising $\mathrm{CO}_{2}$ and global warming play an important role, as suggested by Shindell et al. (1999) and Feldstein (2002), or was the strong positive trend predominantly low frequency natural variability on multidecadal timescales (Schneider et al. 2003; Thompson et al. 2003)? The answer to this question has important implications for possible interdecadal predictability of the NAO and Mediterranean rainfall associated with external forcing. If this winter NAO trend was largely radiatively forced then drier conditions would be expected to continue as atmospheric $\mathrm{CO}_{2}$ rises, consistent with model projections of drying in this region (IPCC 2007). However, if it was dominated by natural variability then wetter conditions may return if the NAO swings to more negative values. To address this issue it is necessary 
Fig. 1 (Top) The change in observed winter Mediterranean precipitation from a linear best fit ( $\mathrm{mm} / \mathrm{month}$ per 30 years) from 1965 to 1994. (Bottom) Timeseries of the 20th Century area mean $(27-52 \mathrm{~N}$,

$15 \mathrm{~W}-50 \mathrm{E}$, land only) winter precipitation in blue and the NAO (inverted) in green, with a linear best-fit line to the precipitation from 1965 to 1994. Results are for the 6-month (November-April) winter mean, using the GPCC $0.5 \times 0.5$ resolution and HadSLP2 $5 \times 5$ resolution datasets
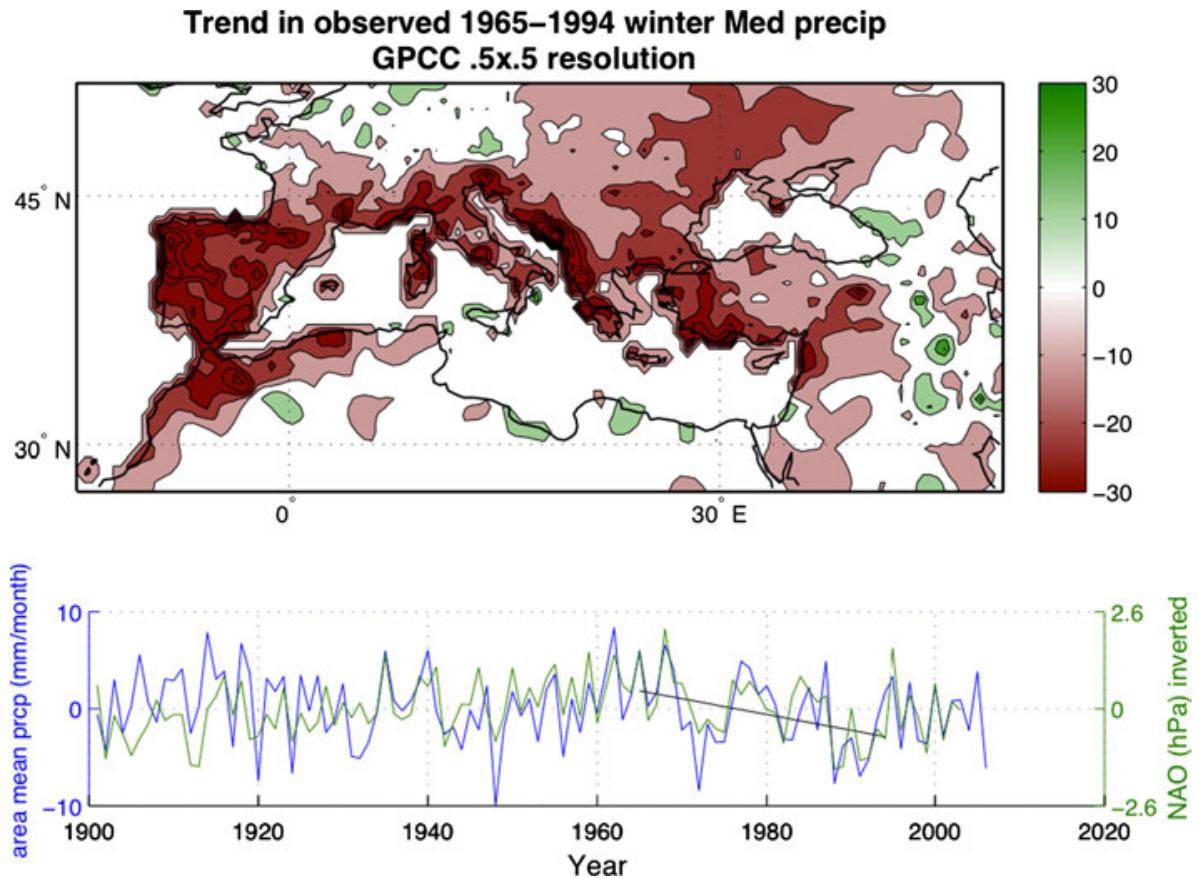

to quantify the relative influence of anthropogenic, or human-induced, external forcing and natural low frequency variability on wintertime NAO and Mediterranean precipitation, allowing for a better assessment of the model projections and how precipitation in the region could change in the future.

There are a number of mechanisms whereby wintertime Mediterranean rainfall could be influenced by anthropogenic and naturally caused external radiative forcing, via both dynamical and thermodynamical processes. These are (1) increases in specific humidity that accompany a warming atmosphere, leading to intensified water vapor divergence in regions where mean flow moisture divergence typically occurs, such as the subtropics in general and the Mediterranean in particular (Held and Soden 2006; Seager et al. 2007, 2010), (2) poleward expansion of the Hadley Cell (Lu et al. 2007), characterized by increased subsidence and suppressed convection on its poleward flank, and (3) northward migration of the northern hemisphere storm track (Yin 2005; Lu et al. 2007, Wu et al. 2010). The Hadley Cell expansion and storm track shift are related phenomena and of particular importance during boreal winter which is the focus of this study. Further, model-projected changes in the NAO cannot fully explain projected drying of the Mediterranean (Previdi and Liepert 2007).

As the leading mode of sea-level pressure (SLP) variability in the North Atlantic (NA) sector, the winter NAO exerts a strong influence over the location of the mean midlatitude storm track that brings transient eddies and rainfall to Europe and the Mediterranean region. It is therefore the dominant influence on Mediterranean rainfall variability during extended winter (November-April) when, over much of the region, the majority of the annual precipitation falls (Hurrell et al. 2003; Dunkeloh and Jacobeit 2003). The spatial pattern of year-to-year Mediterranean rainfall variability associated with the NAO (Cullen and de Menocal 2000) resembles the spatial pattern of the trend in Fig. 1. The well-established negative correlation between winter half-year (November-April) precipitation in the Mediterranean region and the winter NAO is demonstrated in Figs. 1 and 2 (bottom panels) where the timeseries of the area mean $(27-52 \mathrm{~N}, 15 \mathrm{~W}-50 \mathrm{E})$ and the first PC of winter Mediterranean precipitation, respectively, are plotted together with the NAO timeseries (the first PC of NA SLP, here inverted). This comparison with the NAO is made with the caveat that some locations within the area over which the mean was taken have precipitation maximums in seasons other than boreal winter and exhibit trends of opposite sign. However, while these sub-regional differences within the box make using an area mean an inexact characterization of the entire region, the estimate is sufficient to demonstrate the strong correlation with the NAO. Since 1950, as the number of observing stations has increased, the correlations between the two measures of winter precipitation and the winter NAO are 0.77 (Fig. 1) and 0.78 (Fig. 2). From 1900 to the 1960s the winter NAO exhibited a negative trend, accompanied by a modest wetting trend in the Mediterranean. A strong positive NAO trend and robust drying in the Mediterranean followed from the mid-1960s to the '90s. After the late 1990s the NAO index abruptly dropped and then in winter 
Fig. 2 (Top) The first EOF of observed winter Mediterranean precipitation from 1901 to 2007. (Bottom) The corresponding first PC of observed winter precipitation from 1901 to 2007 in blue and the NAO in green, with the linear best-fit to the precipitation from 1965 to 1994 Results are for the NovemberApril mean, using the GPCC $0.5 \times 0.5$ resolution and HadSLP2 $5 \times 5$ resolution datasets
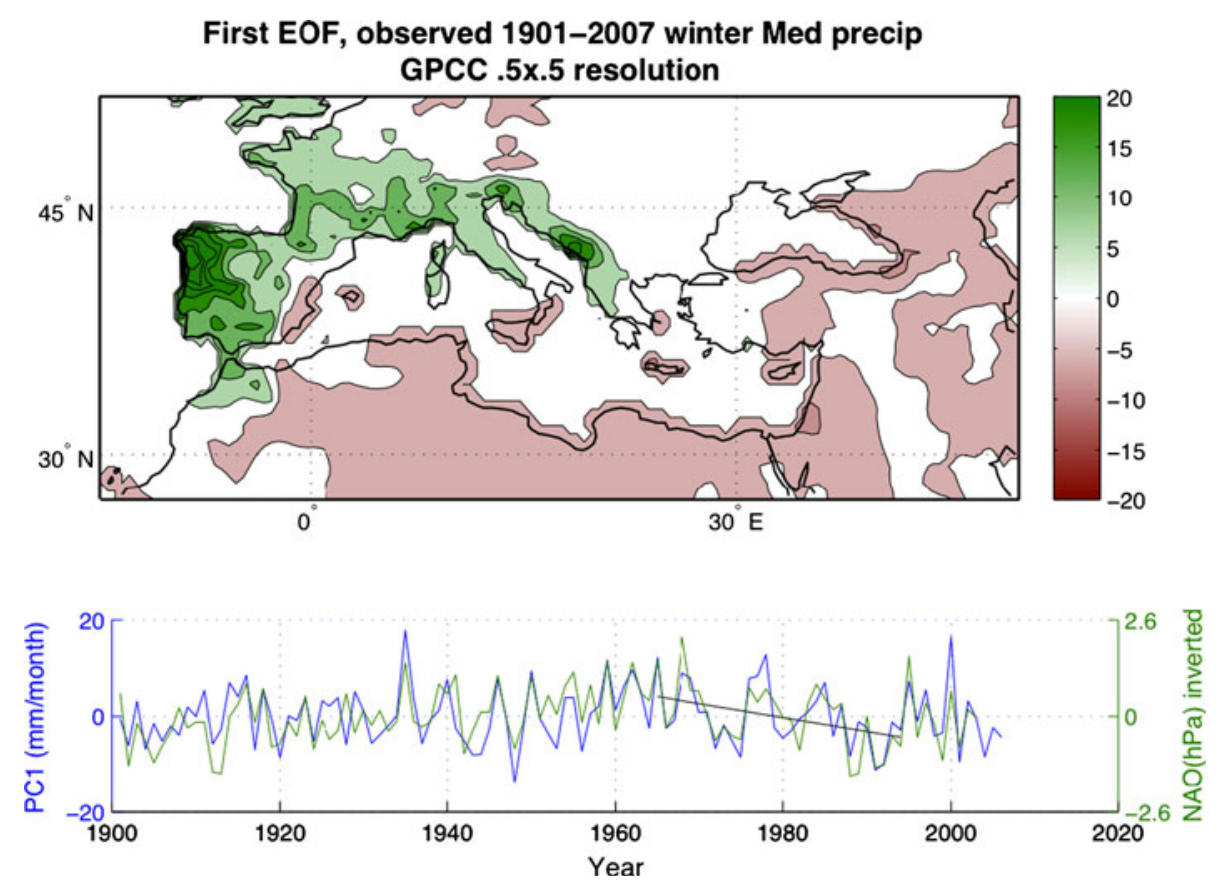

2009-2010 reached its most negative value since 1950 as recorded by the Climate Prediction Center (CPC) NAO Index (not shown) (Barnston and Livezey 1987), while winter Mediterranean precipitation increased. The first EOF pattern of winter Mediterranean precipitation is also shown in Fig. 2 (top) and corresponds to the first PC in the lower panel of the same figure. The first mode over this domain explains $21 \%$ of the total variance in winter precipitation from 1901 to 2007. The winter NAO has also been shown to explain $30 \%$ of the decadal variance in winter (DJF) precipitation in parts of the region (Mariotti and Dell' Aquila 2011). However it is clear from comparing the maps in Figs. 1 and 2 that the NAO cannot fully explain the drying trend in the late 20th Century since the drying occurred across the Mediterranean region whereas NAO-associated drying would be concentrated north of the Mediterranean Sea and in the western half of the basin and cannot explain drying in the eastern basin.

It has been previously reasoned that increasing concentrations of greenhouse gases (GHGs) will induce shifts towards the positive states of the annular modes (Thompson et al. 2000) and the NAO, effectively displacing much of the precipitation that would otherwise fall over southern Europe to northern Europe. However, multidecadal variability in the observed winter NAO and in Mediterranean rainfall (see Mariotti 2010), clearly seen in the 20th Century record and including the recent NAO downturn, raises questions about how much of the observed variations were the result of anthropogenic forcing as opposed to arising from natural variability (Feldstein 2002; Osborn 2004). NAO-related atmospheric variability over different timescales is primarily a result of the internal dynamics of the extratropical atmosphere (Thompson et al. 2003), and it has been argued that this internal atmospheric variability could have been responsible for the observed trends in the winter NAO index (Schneider et al. 2003). However, other studies have argued that the internal variability paradigm does not adequately explain the magnitude of the winter trend observed from the 1960s to the '90s (Thompson et al. 2000; Feldstein 2002).

Using a Markov model constructed from daily atmospheric data, Feldstein (2002) showed that such a strong trend was highly unlikely as a consequence of internal atmospheric variability alone, but that it could occur. Multi-century integrations using atmosphere-ocean coupled climate models have also shown that the late 20th Century positive NAO trend is outside the $95 \%$ confidence interval for internal variability alone (Osborn et al. 1999; Gillett et al. 2003; Osborn 2004), again indicating that the observed trend is highly unusual but still possible. Osborn (2004) argues that the model simulations imply a small contribution from GHG forcing to the observed NAO trend from the 1960 s to the 1990s, and that the observed record can potentially be explained as a combination of internally generated variability and a small GHG-induced positive trend. Osborn points to the downturn since the 1990s in the NAO index as possible evidence of a reversal of the internally generated variation. There is also considerable uncertainty regarding the internal variability, however. Analysis using a 40-member CCSM3 ensemble from 2005 to 2060 showed that internal atmospheric variability associated with the annular modes 
is the dominant source of uncertainty in the simulated climate response in the middle and high latitudes, accounting for at least half of the inter-model spread (Deser et al. 2011). Atmospheric interaction with the extratropical and tropical oceans has also been put forth as a possible explanation for the low frequency variability of the NAO (Kushnir et al. 2006). For example, it has been shown by forcing an AGCM with global SSTs and sea-ice distributions, that half of the amplitude in longterm wintertime NAO variability can be simulated with, in particular, tropical SST forcing dominated by warming in the Indo-Pacific (likely partly driven by rising GHGs), explaining some of the observed winter trend since 1950 (Hoerling et al. 2001; Hurrell et al. 2006). Mariotti et al. (2008) concluded from the CMIP3 simulations that a transition to drier conditions is already under way, has begun to accelerate, and that observed 20th Century trends in regionally averaged precipitation, Palmer Drought Severity Index (PDSI) and Mediterranean Sea salinity support the simulations. If the CMIP3 projections are correct, the Mediterranean water cycle could be dramatically altered by the end of the 21st Century, with a $20 \%$ decrease in land surface water availability resulting from reduced precipitation (Mariotti et al. 2008). If in fact anthropogenic forcing has already begun to exert a measurable influence over North Atlantic SLP and Mediterranean precipitation during winter then it is reasonable to expect that influence to increase during the current century relative to the natural variability. In summary, previous studies imply that external forcing could have been partially responsible for the winter NAO trend during this time, but to what extent and how the externally forced responses in both the NAO and in winter Mediterranean rainfall contribute to the total observed trend and its spatial variation remain largely unanswered.

To improve understanding of recent precipitation change in the Mediterranean region we first determine whether the observed 1960s to 1990 s winter NAO and precipitation trends fall within the range of running 30-year trends simulated by the Intergovernmental Panel on Climate Change Assessment Report Four (IPCC AR4) Coupled Model Intercomparison Project (CMIP3) models over the 20th Century. We then use a signal-to-noise maximizing EOF technique (see Sect. 2 below) to obtain a model-based best estimate of the externally forced signal and use regression to divide up the observed winter trends in NA SLP and Mediterranean rainfall from 1960 to 1999 into internal and forced components. We conclude that the internal variability was dominant, with a small contribution from the external forcing, but that if the model simulated signal is realistic then the externally forced contribution to Mediterranean winter drying will increase over the $21 \mathrm{st}$ Century.

\section{Data and methods}

\subsection{Observed data}

We use the observed monthly sea level pressure from the Hadley Centre HadSLP2 dataset, which covers the period from January 1850 to December 2004 (Allan and Ansell 2006). The monthly SLP has been regridded to $2.5^{\circ}$ latitude by $2.5^{\circ}$ longitude resolution from its original resolution $\left(5^{\circ}\right.$ by $5^{\circ}$ ), consistent with the model data, and averaged over the extended winter season from November to April for the North Atlantic and Europe domain $\left(75^{\circ} \mathrm{W}-50^{\circ} \mathrm{E} 15^{\circ}\right.$ $75^{\circ} \mathrm{N}$ ). For observed precipitation we use the Global Precipitation Climatology Centre (GPCC) Full Data Product version 4 from the World Climate Research Programme (WCRP) Global Climate Observing System (GCOS), from January 1900 through December 2007 (Schneider et al. 2008). These data are available over land only. The resolution of the precipitation data is $0.5^{\circ}$ latitude by $0.5^{\circ}$ longitude, and we time average the data for the same extended winter season (November-April) for the Mediterranean region (15 W-50 E 27-52 N), (see Fig. 1).

\subsection{Model simulations}

For model data, we use 19 coupled CMIP3 models (Meehl et al. 2007) assessed within the IPCC AR4 (see Table 1), including all runs with available SLP and precipitation data

Table 1 CMIP3 models used in this study, their country of origin and the dimensions of their horizontal grids

\begin{tabular}{llc}
\hline Model & Country & Horizontal grid size \\
\hline CGCM3.1 T47 & Canada & $96 \times 48$ \\
CNRM CM3 & France & $128 \times 64$ \\
CSIRO MK3.0 & Australia & $192 \times 96$ \\
GFDL CM2.0 & USA & $144 \times 90$ \\
GFDLCM2.1 & USA & $144 \times 90$ \\
GISS AOM & USA & $90 \times 60$ \\
GISS-EH & USA & $72 \times 46$ \\
GISS-ER & USA & $72 \times 46$ \\
IAP FGOALS & China & $128 \times 60$ \\
INMCM3-0 & Russia & $72 \times 45$ \\
IPSL CM4 & France & $96 \times 72$ \\
MIROC3-2-hires & Japan & $320 \times 160$ \\
MIROC3-2-medres & Japan & $128 \times 64$ \\
MPI ECHAM5 & Germany & $192 \times 96$ \\
MRI CGCM2.3.2a & Japan & $128 \times 64$ \\
NCAR CCSM3.0 & USA & $256 \times 128$ \\
NCAR PCM1 & USA & $128 \times 64$ \\
UKMO HADCM3 & UK & $96 \times 73$ \\
UKMO HADGEM1 & UK & $192 \times 145$ \\
\hline
\end{tabular}


over the 20th and 21st Centuries (46 total runs), with some models having single and others multiple runs. The $21 \mathrm{st}$ Century model projections are based on the so-called 'middle-of-the-road' A1B emissions scenario (Nakicenovic and Swart 2000). For preindustrial runs, the same 19 models were used. All models are re-gridded to a common $2.5^{\circ}$ latitude by $2.5^{\circ}$ longitude resolution. Spatial domains and temporal averaging are the same as for the observed.

\subsection{Methods}

There are two primary methods that are traditionally used to define the NAO. The first is indexing using normalized pressure differences between pairs of stations representing the northern and southern SLP nodes. The second definition, and the one adopted in this study, is based on empirical orthogonal function (EOF) analysis using area weighted SLP over the North Atlantic domain $\left(75^{\circ} \mathrm{W}-50^{\circ} \mathrm{E}\right.$ $\left.15^{\circ}-75^{\circ} \mathrm{N}\right)$. The first principal component (PC1) and empirical orthogonal function (EOF1) of SLP represent the temporal and spatial variation of the NAO. The two methods are highly correlated (Hurrell et al. 2003). Similarly, the model NAOs were determined by EOF analysis for each individual model run. The pattern correlations between each model simulated NAO and the observed NAO pattern were calculated, for validation purposes. For Mediterranean precipitation indices the first principal component over the domain ( $15 \mathrm{~W}-50 \mathrm{E} 27-52 \mathrm{~N})$ was used rather than the timeseries of the spatial mean due to the large spatial variation within the domain. We also recognize that the spatial resolution of the CMIP3 models used in this study is insufficient to resolve sub-gridscale orographically-induced modifications to the mean flow precipitation and realistic Mediterranean cyclogenesis, and that these shortcomings add uncertainty to any results. However, the CMIP3 models produce 20th Century climatologies that are well correlated with observations over the Mediterranean region as a whole. The area-weighted spatial correlations between the 20th Century time-averaged Mediterranean (27-52 N, 15 W-50 E, land only) winter precipitation for the observations and the first run of each of the 19 models all exceed 0.72. Although higher correlations could be desired, we feel that the models represent the variability in space and time sufficient for use in this study. It is the authors' intention to investigate the higher-resolution CMIP5 models as they become available.

We computed running 30-year trends for the NAO and Mediterranean precipitation indices for both models and observations. In our running trend analysis we use a time step of 5 years, with trends calculated as linear least squares fits to the first PCs, resulting in fifteen 30-year trends over 100 years for the observed and $690(15 \times 46$ runs) trends for the models. For this part of the analysis we used 46 runs in the 20th Century, consistent with the number of runs available in the 21st Century. Trend magnitude, or total change in the linear trend, is simply represented by the difference between the last value and the first value in the linear best fit. Statistical significance of regression coefficients was performed using a student's t-test, assuming a Gaussian distribution. Multidecadal variabilities of the observed and modeled NAO are further compared by applying a low pass Butterworth filter with a 9-year cutoff to the SLP and representing the NAO as the PC of the first EOF of these SLP fields.

After testing whether the 20th Century model-simulated 30 -year trends are able to span the range of observed trends we use signal-to-noise $(\mathrm{S} / \mathrm{N})$ maximizing EOF analysis (Allen and Smith 1997; Venzke et al. 1999; Chang et al. 2000; Ting et al. 2009) applied to NA SLP and Mediterranean precipitation in boreal winter. There are two primary reasons for utilizing this approach rather than simply using a multimodel mean: first, it provides an optimized timeseries (signal) onto which the observations may be regressed, and secondly the available sample size of models and the use of many different models with possibly different responses to forcing means that natural variations cannot be removed, and the forcing isolated, simply by averaging across the ensemble. This technique should help eliminate contamination by noise resulting from the size and nature of the sample. In order to retain only the decadal and longer timescale variations in the NA SLP and Mediterranean precipitation we employ a 9-year low pass Butterworth filter prior to application of the $\mathrm{S} / \mathrm{N}$ maximizing EOF.

The terminology of "signal-to-noise $(\mathrm{S} / \mathrm{N})$ maximizing EOF analysis" refers to a method of identifying the "common" response to external forcing from an ensemble of forced GCM experiments. Here we follow the formulation proposed by Venzke et al. (1999) and Chang et al. (2000), using the method to distinguish between the climate response to prescribed external forcing common to all ensemble members, hereafter referred to as "the signal", and internal variability, which is temporally uncorrelated between ensemble members. We use a multimodel ensemble, constructed using one realization from each of the 19 CMIP3 models for the 20th Century. As in Venzke et al. (1999) we assume that the total covariance matrix is a sum of two linearly independent matrices, one for the forced signal and the other for internal variability or "climate noise." When, as we expect, there is spatial correlation in the climate noise, the EOFs of the total covariance matrix will constitute a mix between the patterns of the signal and those of the noise. To untangle the mix and remove the signature of the noise a "pre-whitening" procedure is applied to the covariance matrix, which amounts to projecting the variability on the leading EOFs of the 
noise covariance matrix. Under the linear independence assumption, this operation diagonalizes the noise component of the covariance matrix and the resulting matrix is not affected by the spatial structure of the latter (adding a diagonal matrix to another symmetric matrix does not affect the EOFs of the former, see Venzke et al. 1999 for details). In our particular application of the procedure, we used the last 100 year preindustrial integrations of 19 available multi-model ensemble members to estimate the climate noise EOFs for the pre-whitening procedure. For each model the 100-year mean is subtracted first and all the preindustrial model anomalies are then pooled to calculate the noise EOFs. In this way, model biases in representing the variability are included in the noise.

After we obtain the model-derived best estimate of the forced signal ( $\mathrm{PC} 1$ of the $\mathrm{S} / \mathrm{N}$ EOF) we regress the observed 20th Century data fields of SLP $(\mathrm{x}, \mathrm{y}, \mathrm{t})$ and precipitation $(\mathrm{x}, \mathrm{y}, \mathrm{t})$ onto it as:

$\alpha(x, y)=\operatorname{corr}(x, y) \frac{\sigma(\operatorname{variable}(t))}{\sigma(\operatorname{PC} 1(t))}$

where $\operatorname{corr}(x, y)$ is the time correlation and $\sigma$ is the standard deviation, thus obtaining spatial patterns of the forced regression coefficients, $\alpha(x, y)$. We can then reconstruct the externally forced portion of $\operatorname{SLP}^{*}(x, y, t)$ [or $\left.\operatorname{precip}^{*}(x, y, t)\right]$ in time and space as follows:

$\operatorname{SLP}^{*}(x, y, t)=\alpha(x, y) * \operatorname{PC} 1(t)$

The reconstructed externally forced field is then subtracted from the total field to get the residual internal component:

$\operatorname{SLP}^{\text {resid }}(x, y, t)=\operatorname{SLP}(x, y, t)-\operatorname{SLP}^{*}(x, y, t)$

The total, externally and internally forced SLP (and precipitation) trends from 1960 to 2000 can then be computed as the linear trends of SLP, SLP* and SLP ${ }^{\text {resid }}$, respectively.

\section{Modeled and observed trends in winter NA SLP and Mediterranean precipitation}

\subsection{0th Century SLP trends}

To determine whether the observed NAO trend from 1965 to 1995 is outside the range of what the 19 IPCC AR4 models simulate, and to assess the overall capability of the multimodel ensemble to produce NAO trends of magnitude comparable to those observed in the 20th Century, we begin by examining running 30 -year trends of each model's NAO (first mode of SLP variability). A distribution of modeled trends is then created for each trend period, beginning with 1900-1930 and advancing in 5-year increments to the final trend, 1970-2000. Figure 3a (top) shows the time evolution and spread of the modeled 30 -year NAO trends. Each box plot contains 46 modelproduced trends for the respective period and includes the quartiles, medians, means, whiskers and outliers. Whiskers extend from each box to the maximum trend values that fall within 1.5 times the interquartile range, and the outliers are represented as red crosses. The observed 30-year trends are also shown in each box, as black asterisks. All of the observed trends, ranging from -1 to $1.7 \mathrm{~h} \mathrm{~Pa} / 30$ years, are within the total spread of the simulated trends, which span -2 to $+2.5 \mathrm{~h} \mathrm{~Pa} / 30$ years. The strongest observed trend (from 1965 to 1995) is the only observed trend outside the respective whisker interval of modeled trends of the same time period but falls within the full 20th Century range of most negative and most positive model simulated trends.

The time evolution of the observed 30-year trends reflects the multidecadal variability of the NAO with downward trends in the early part of the 20th Century and upward trends afterwards. The mean of the modeled trends for each period (indicated with a blue cross) has markedly smaller trends than the observed NAO trends. This should be expected if the observed and modeled trends arise from internal variability because the model mean is an average across models with differing out-ofphase variability. To the extent that the model mean or median trends can be taken as estimates of the radiatively forced NAO trend, and the spreads as the range of natural variability, the forced trends are small at all times indicating that the observed trend from 1965 to 1995 is mostly a result of natural variability rather than external forcing.

However, because the forced signal and the response to given forcings are not necessarily the same in each model, a multimodel ensemble mean may not be a precise characterization of the externally forced portion of NAO trends. Therefore, removing the ensemble mean from each run does not necessarily represent the intrinsic climate variability of that run, motivating the signal to noise maximizing EOF approach used below.

\subsection{0th Century precipitation trends}

We also apply the running trend analysis to the first mode of Mediterranean winter precipitation and show the results in Fig. 3b (bottom). In the observations and in the model simulations the largest 30-year precipitation trends are on the order of $\pm 9 \mathrm{~mm} / \mathrm{month} / 30$ years. Twice, from 1940 to 1970 and from 1965 to 1995 , the observed trends were outside the whisker interval of the simulations for that particular time period. However, as with the NAO trends, all of the observed 30-year trends in the first PC of 

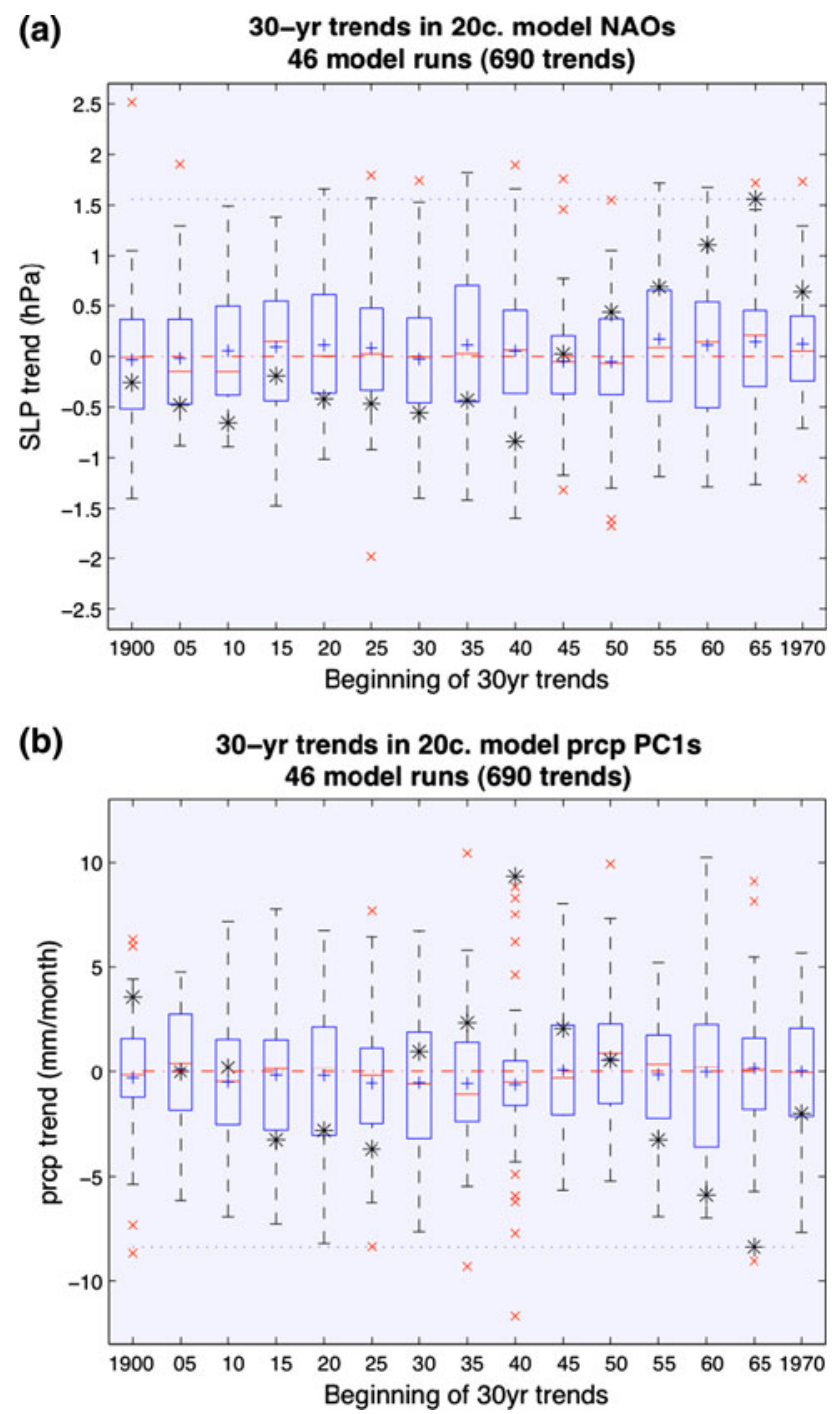

Fig. 3 Box plots of running 30-year trends in the NAO (top) and Mediterranean precipitation (bottom) (first PC) from 1900 to 2000, in 5 -year time step increments, using the first PC of 46 available runs from 19 CMIP3 models. Each box has lines at the lower quartile, median, and upper quartile values. Whiskers extend from each end of each box to the maximum values within 1.5 times the interquartile range. Blue crosses represent the means of each distribution, and red $x$ 's indicate outliers, or values outside the whiskers. HadSLP2 and GPCC observed trends are shown as black asterisks. Units are $\mathrm{h} \mathrm{Pa}$ per 30 years and $\mathrm{mm} /$ month per 30 years, using the November-April mean

Mediterranean precipitation are within the overall 20th Century distribution (i.e. within the range of most negative and most positive values) of modeled 30-year trends during the entire century. Hence, the individual simulations can produce multidecadal variability that resembles the observations even though most of the observed 30 year trends of the winter NAO and precipitation are outside the 25th and 75th percentiles of the time-corresponding modeled trend distributions.
3.3 Temporal behavior of 20th Century observed and modeled SLP and precipitation

In order to compare observed and model simulated variability at all timescales 10 years or longer, we apply a 9-year low pass filter to the observed and model-simulated runs for the 20th Century and then calculate the NAO and precipitation timeseries from the first modes. It can be seen from six of the coupled models (Fig. 4) that the differences between the most positive and most negative values in the modeled low-frequency NAO and precipitation timeseries over the century are similar to the observed. The decadal to interdecadal variability in the six models shown is representative of all 19 models (not shown). Additionally, the fraction of total variance of total winter SLP and precipitation variability explained by the first modes for the observations $(\sim 40 \%)$ are near the center of the spreads of the variance explained by the first mode for all 19 models. Based on visual examination of the spatial patterns (not shown) of the first modes, the models as a whole represent the observed NAO pattern fairly well, with some differences in the location of the dipoles with respect to the observed NAO. The area-weighted spatial correlations between the models' NAO patterns and the observed NAO pattern range from 0.78 to 0.98 . The observed and modeled NAOs and first modes of precipitation show marked multidecadal variability at different timescales. The difference between observed and modeled low frequency variability in the first mode of precipitation is less distinct than for the NAO. The observed low-frequency NAO during the 20th Century is dominated by 30-60-year half-oscillations, compared with 10-15 year half-oscillations in the simulations. This difference is consistent with the observed 30 -year trends being outside the 25 th and 75 th percentiles of the modeled trend distributions. Despite the differences in low frequency variability compared to the 20th Century observations, the models do a credible job of simulating the character of the variability of the winter NAO and can create 30-year NAO trends of comparable magnitude to those observed during the 20th Century, although not as often.

\subsection{Comparing observed and modeled SLP} and precipitation trends from the preindustrial era through the 21st Century

In Fig. 5 we show histograms of all model simulated 30-year winter NAO and Mediterranean precipitation (first mode) trends, for preindustrial, 20th Century and 21st Century runs, as well as for a 600-year tree-ring NAO reconstruction (Cook et al. 2002). The means, standard deviations, skewness, and Chi-squared goodness of fit statistics of each histogram are shown. A value of zero for 
(a) Observed and model-simulated 9-year low pass filtered NAO and first mode of Mediterranean winter precipitation

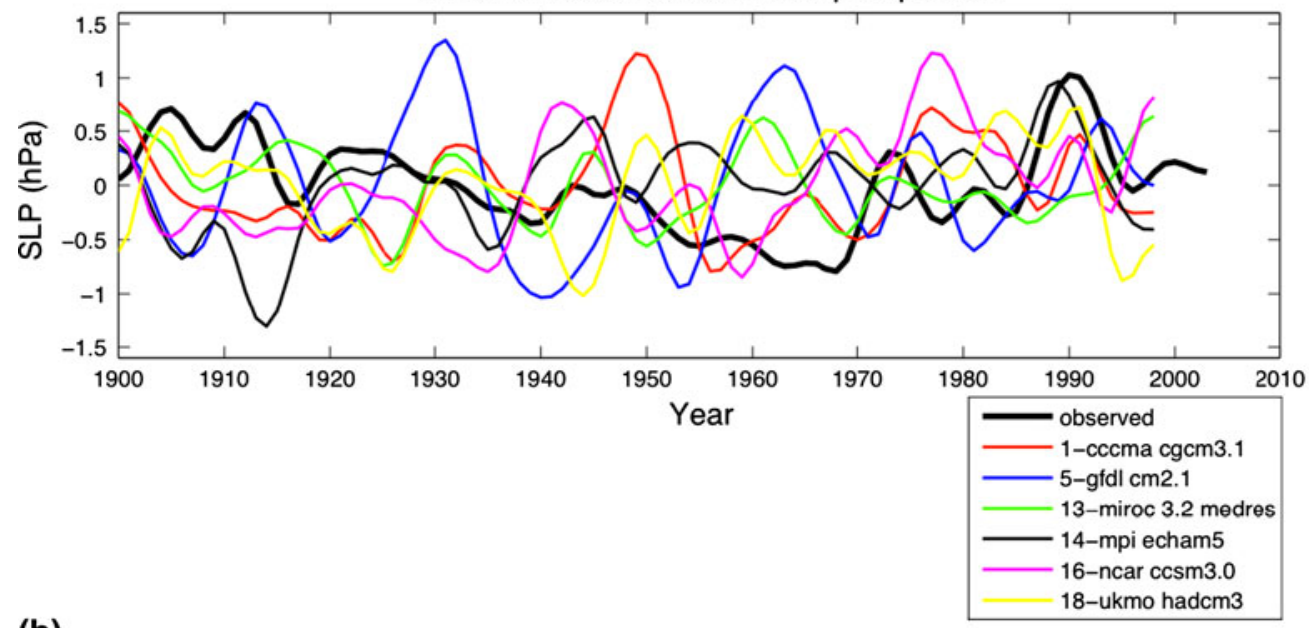

(b)

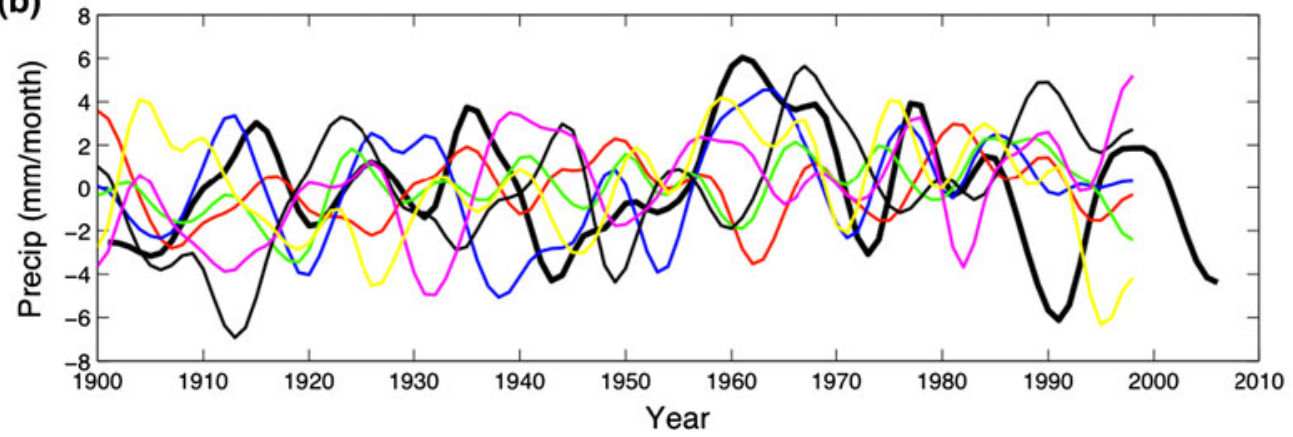

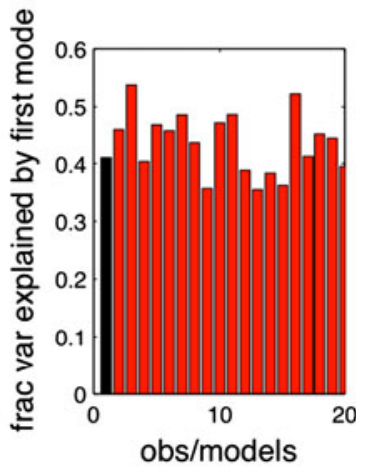

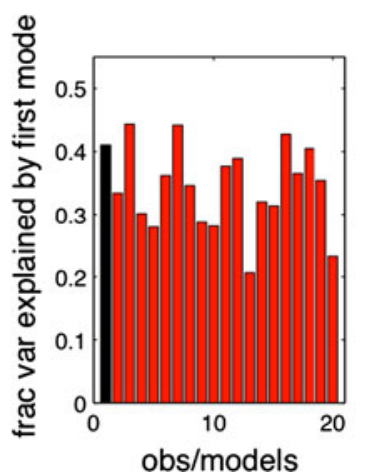

Fig. 4 Time series of 20th century observed and model simulated NAOs, calculated as the first modes of SLP (top) and Mediterranean precipitation (bottom) derived from 9-year low pass filtering, in $\mathrm{h} \mathrm{Pa}$ and $\mathrm{mm} / \mathrm{month}$. Six coupled models are shown at left. The panel on

the Chi-squared statistic indicates that the null hypothesis (no difference from a Gaussian distribution) cannot be rejected, here using a $90 \%$ confidence interval. For the $\mathrm{NAO}$, the mean and median of the 30-year model simulated trends during the 20th Century (left column, second panel from top) are 0.06 and 0.02 ( $\mathrm{h} \mathrm{Pa} / 30$ years), with a SD of 0.67 , and the distribution is skewed slightly right. The Chi-squared statistic indicates a rejection of the null hypothesis, indicating that the data are not a random sample from a normal distribution at this confidence level. As in Fig. 3 it can be seen that the observed winter NAO trend from 1965 to 1995 is within the distribution, although the number of positive trends simulated by the models that exceed this trend is small. Based on the first mode of winter precipitation, the modeled 30-year trend distribution has a mean and median of -0.18 and -0.16 (mm/month/ 30 years), and a standard deviation of 3.3. Unlike for the NAO distribution, the Chi-squared statistic indicates a normal distribution for the 20th Century modeled precipitation based on the confidence interval. The observed trend from 1965 to 1995 is shown, and the number of model- the right displays the fraction of total variance explained by the first mode for the observations and the 19 CMIP3 models, using the November-April mean

simulated trends exceeding this value is also small, although greater than for the NAO case.

Because it is possible that different models will have different responses to even the same forcings and also there are differences in how the models are forced, we therefore turned to the preindustrial runs of the models as an alternate means of determining the NAO trends resulting from each model's internal variability alone. Preindustrial runs also provide the benefit of a longer period with which to characterize multidecadal internal variability in the models. The top panels in Fig. 5a, e show that the modeled distributions of these 30-year trends, using a larger sample size, are essentially Gaussian. The observed trends from 1965 to 1995 fall inside the distributions, supporting the finding that these trends are likely due in large part to internal climate variability.

The bottom panel of Fig. 5d shows NAO trends calculated from a 600-year winter (Dec-Mar) NAO index reconstruction (1400-2001) using tree-ring records (Cook et al. 2002) that span the transition from the preindustrial to the present and are used for comparison with the model- 
Fig. 5 Histograms of running 30-year trends in the NAO (left) and Mediterranean precipitation first mode (right), in 5-year time step increments. From top to bottom: 19 preindustrial runs (of varying length for each model); 46 runs during the 20th Century; 46 runs during the 21 st Century; and a 600 year tree ring NAO reconstruction from 1400 to 2000 (left). Results are for the November-April mean. The trend units are in $\mathrm{h} \mathrm{Pa}$ and $\mathrm{mm} / \mathrm{month}$, per 30 years

Histograms of running 30-yr trends

SLP

(a) Preindustrial model runs (19 models, one run each, 1509 trends)

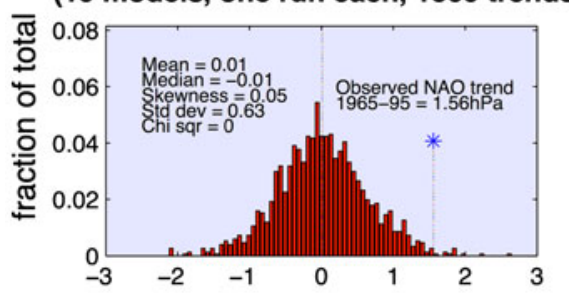

(b) 20c. model runs (19 models, 46 runs, 690 trends)

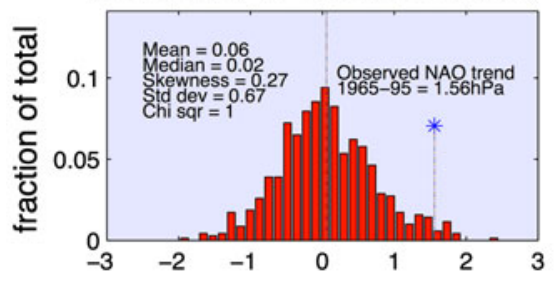

(c) 21c. model runs 19 models, 46 runs, 690 trends)

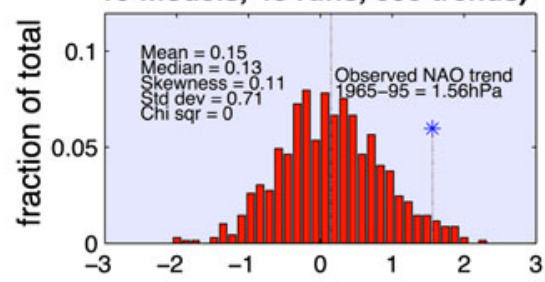

(d) Tree ring reconstructions 1400-2000 (115 trends)

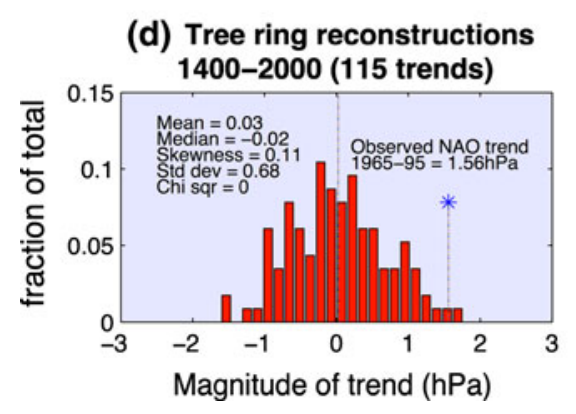

Precipitation

(e) Preindustrial model runs (19 models, one run each, (1509 trends)

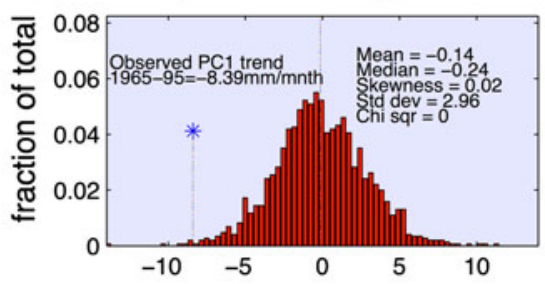

(f) 20c. model runs (19 models, 46 runs, 690 trends)

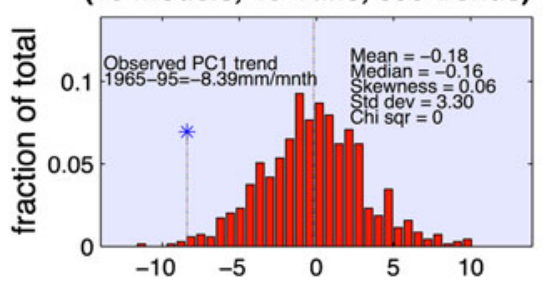

(g) 21c. model runs

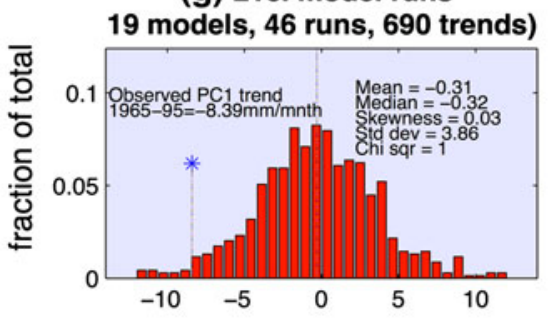

simulated trends. Before calculating the trends using this reconstruction, it was necessary to rescale the mean and standard deviation of the timeseries to match the mean and standard deviation calculated from the observed winter (November-April) NAO (first mode of SLP) from 1980 to 2000. Applying the 9-year low pass filter to the winter NAO tree-ring reconstruction reveals that some 100 year periods (not shown) more closely resemble the low frequency temporal variability of the 20th Century observed winter NAO timeseries, while others are more similar to the variability of the model simulated NAOs during the 20th Century. This indicates that the observed low frequency winter NAO variability in the 20th Century may be atypical compared to several of the previous centuries. Even though the distribution is based on a smaller sample size, the mean (0.03), skewness (0.11) and standard deviation (0.68) shown in Fig. $5 \mathrm{~d}$ are consistent with the range of statistics for the larger samples of the preindustrial, 20th and 21st Century histograms in Fig. 5a, b and c. NAO trends of magnitude greater than the observed trend from 1965 to 1995 although rare have occurred over the last 600 years according to this NAO reconstruction.

It can be seen (Fig. 5, left) that as the external forcing increases with time, from the pre-industrial through the 21 st Century, the mean of the modeled NAO trend distribution increases indicating a tendency toward an increasing 
number of positive 30 -year NAO trends. This positive shift in the mean trend of the distribution is accompanied by a small increase in the standard deviation of the trend distribution, indicating a widening of the distribution or an increase in the number of strong positive and negative 30-year trends as the external forcing increases. The opposite shift in means can be seen in the Mediterranean precipitation trends (Fig. 5, right), but like the NAO case there is an increase in the standard deviation of the trends. In this case however the increase is much stronger, particularly from the 20th to the 21st Century, leading to stronger 30-year precipitation trends, both positive and negative. The z-score (based on a normal distribution) or pooled standard error of the pre-industrial and 20th Century NAO trends is 1.26 , indicating that the shift in the means is well below the $90 \%$ confidence interval threshold. This is not the case when comparing the pre-industrial to the 21st Century, however, as the z-score is 3.67, demonstrating a highly significant shift in the mean 30 year NAO trend. For the precipitation, the corresponding $\mathrm{z}$-scores are 0.47 and 1.91 respectively, again indicating significance of the mean shift at the $90 \%$ level for the 21 st Century, although less so than for the NAO. The magnitude of the observed NAO and precipitation trends from 1965 to 1995 ( $1.56 \mathrm{~h} \mathrm{~Pa}$ and $-8.39 \mathrm{~mm}$ per month per 30 years) is shown in each panel, and it can be seen that the models are more likely to produce trends that exceed the observed trend when radiative forcing is included, during the 20th Century and 21st Century, but that even in the pre-industrial distribution the strong observed trend is not entirely outside the range of model-simulated 30-year NAO trends. Unlike the 20th Century, the Chi-squared statistic for the 21st Century histograms indicates a normal distribution for the NAO trends, but a rejection of the null hypothesis for the precipitation trends based on a $90 \%$ confidence interval.

In all, the capability of the models to produce NAO and precipitation trends with a reasonable magnitude lends confidence in their suitability for creating a best estimate of the externally forced low frequency variability in both NA SLP and Mediterranean rainfall through the use of signalto-noise EOF maximization.

\section{Externally forced variability using signal-to-noise maximization EOF}

To determine quantitatively the NAO and Mediterranean rainfall trends due to external forcing versus internal climate variability we use the signal-to-noise maximizing EOF method (Chang et al. 2000; Ting et al. 2009 and see Sect. 2). In this section the signal-to-noise EOF is applied to NA SLP (75 W-50 E 15-75 N) and Mediterranean precipitation (15 W-50 E 27-52 N) using one run of each of the 19 CMIP3 coupled models to calculate the multimodel ensemble mean, and using the last century from the preindustrial runs of the same models for the noise covariance matrix. Figure 6 shows the leading modes of the model-derived externally forced responses of NA SLP and Mediterranean precipitation calculated from the 20th Century (left) and from the 20th and 21st Centuries combined (right). For the two centuries combined, the first mode in each case explains approximately $74 \%$ (top) and $85 \%$ (bottom) of the total variance respectively (of SLP and precipitation), dominated by the strong trend in the 21 st Century. The timeseries associated with the SLP and precipitation responses to the external forcing (the "signals") mirror each other well, showing an initial change several decades prior to the end of the 20th Century and continuing in a steady fashion with a positive NAO trend, and Mediterranean drying, through the end of the 21st Century, consistent with Mariotti et al. (2008). The spatial structures are also consistent, with reduced rainfall under increasing SLP. Although there are some differences between the first EOFs and the canonical observed NAO pattern, the structures are very NAO-like. It is interesting to note that the combined 20-21st Century first modes of SLP and precipitation have eastern and western maxima compared to a single maximum in the 20th Century, although the reason for this difference is unclear.

Taking the model-derived signals (timeseries) to be our best estimate of the externally forced responses we regress the observed NA SLP and Mediterranean precipitation for the extended boreal winter onto the 20th Century time series shown in Fig. 6 (left). The total SLP (precipitation) anomalies are then separated into two parts, one associated with the external forcing (Eq. 2, above) and another with internal variability (Eq. 3), which again includes any intermodel differences in response to forcing. The trends over the last 40 years of the 20th Century (in order to fully capture the beginning and end of the strongest 30-year trend) are then calculated for the three sub-components (total, external, residual). This provides us with a best estimate of the forced trend based on combining models and observations. The three trends for SLP are shown in Fig. 7, along with the multimodel mean trend for the same period. It can be seen that the magnitude of the total trend (top left) is only slightly larger than the residual trend (bottom left), which appears to be roughly three times larger than the externally forced trend (top right). We can quantify the portion of the total trend for which the external forcing is responsible by taking the ratio of the root mean square (calculated over the domain) of the two trend patterns, externally forced and total, and the result is $33 \%$. The stippling in Fig. 7 indicates the statistically significant regression coefficients (outside a 90\% confidence interval). The two areas in Fig. 7 (top right) where externally forced 
Fig. 6 First modes of the signal-to-noise maximizing EOF of (top) North Atlantic SLP and (bottom)

Mediterranean precipitation (inverted) for the 20th (left) and 20-21st centuries (right) using the preindustrial, 20th and 21st Century runs from 19 CMIP3 models. A 9-year Butterworth low pass filter was applied prior to maximization. Results are for the November-April mean. Units are in SD of the pattern and of the time series, respectively 20th c.

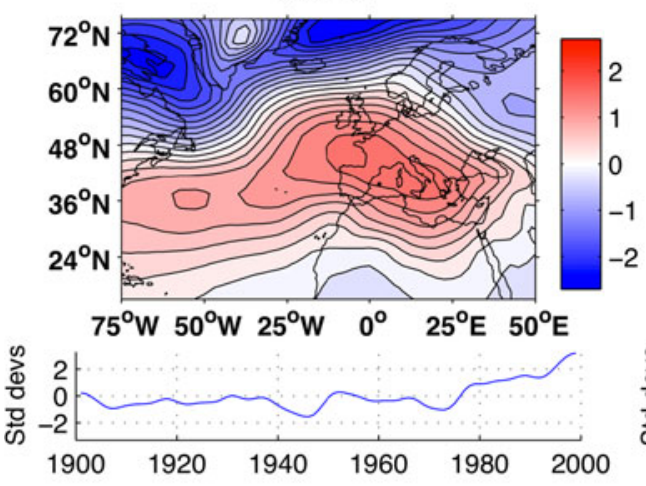

20th c.
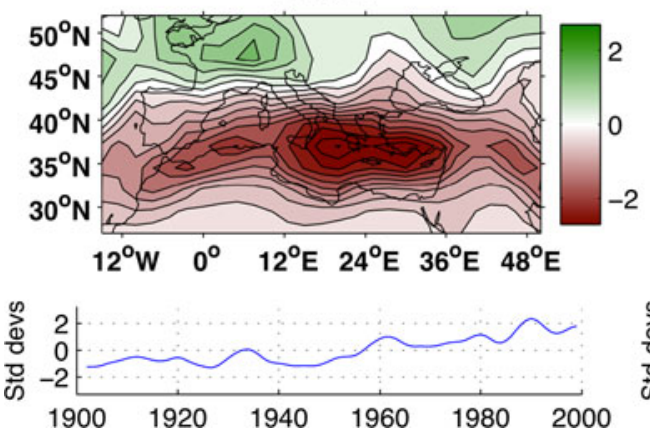

20th and 21st c.

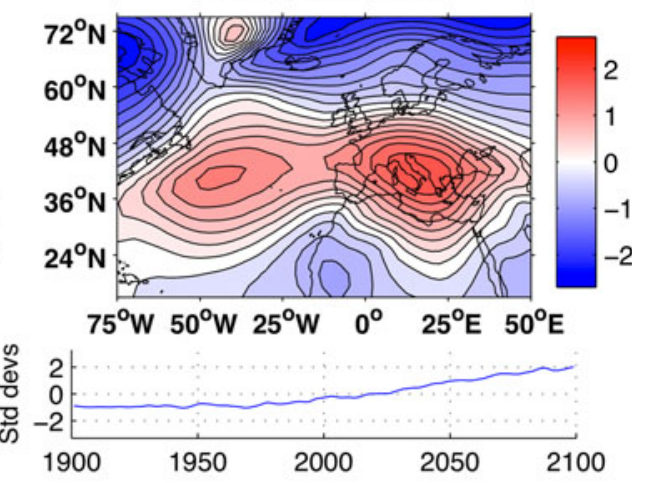

20th and 21st c.
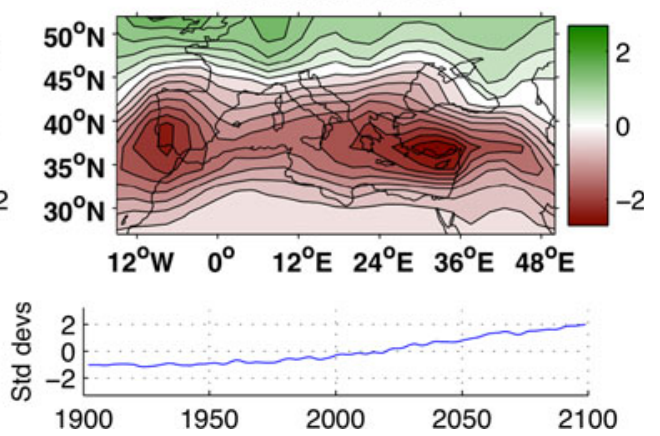

trends are consistently significant are over the Labrador Sea and Mediterranean Basin respectively. Both the forced and residual SLP trend patterns resemble a positive NAO over the NA and Europe, in the sense of lower SLP in subpolar regions and increased SLP in the subtropics. However, it is a curious feature that over the Labrador Sea the external and internal trends oppose each other, with the internal trend dominating. Directly over the Mediterranean region the externally forced and residual SLP trends appear comparable in magnitude, which would seem to indicate that the external trend in SLP was in fact relevant.

Although for the NA region as a whole it is much smaller than the residual trend, the overall magnitude of the externally forced NA SLP trend is slightly larger than the magnitude of the multimodel mean trend (Fig. 7, bottom right). Notice that multimodel trends do not take into account any of the observational information and are purely model-produced, whereas the forced trend (Fig. 7, top right) is estimated using information from both observations and models. Both estimates contain substantial errors, but looking at both provides a range of possible amplitudes for the externally forced observed trends. A simple multimodel mean not only includes some noise contamination when the sample size is sub-optimal, but could also average out some intermodel differences in external forcing and response. Alternatively, regressing observed data onto a model-derived signal to obtain the externally forced part of the observed trend implies that the observed signal and model-derived signal are similar, which is not necessarily the case.

In Fig. 8 we show the same attribution as in Fig. 7 but now for the winter precipitation trend over the Mediterranean region. The overall rainfall trend pattern attributable to external forcing is much weaker than the residual trend arising from internal variability over most of the region. The ratio of the root mean squared externally forced and total trend patterns in this case is only $21 \%$, indicating only a modest fraction of the total drying trend was externally forced. Nearly all of the strong drying observed over Ionia, the African coast north of the Atlas Mountains and over most of the Alps and Italy is due to the residual trend due to internal variability, with little contribution from the external forcing. There is considerable disagreement in sign between the two patterns over northern Europe and the Eastern Mediterranean. In the latter region there is strong, statistically significant drying in the externally forced pattern but statistically significant wetting in the residual, consistent with the sign of the NAO-induced precipitation anomalies in this region (Fig. 2). The only sub-region over which the externally forced drying approaches the magnitude of residual drying is along the eastern Adriatic coastline, predominantly over Montenegro and Albania. Also, over much of northern Africa the residual, internal variability, trend is positive, while the externally forced trend is 
Fig. 7 Attribution of observed North Atlantic SLP trend over 1960-2000. Clockwise from top left are shown: a total trend, b externally forced trend, c multimodel mean trend, d residual trend including natural variability. Color scales apply to top and bottom panels. Trends are the change based on a linear best fit, with units of h Pa per 40 years. Results are for the November-April mean

Fig. 8 Attribution of observed Mediterranean precipitation trend for 1960-2000. Clockwise from top left are: a total trend, b externally forced trend, c multimodel mean trend, d residual trend including natural variability. Color scales apply to top and bottom panels. Trends are the change based on a linear best fit, with units of $\mathrm{mm} / \mathrm{month}$ per 40 years. Results are for the November-April mean

\section{Total trend}
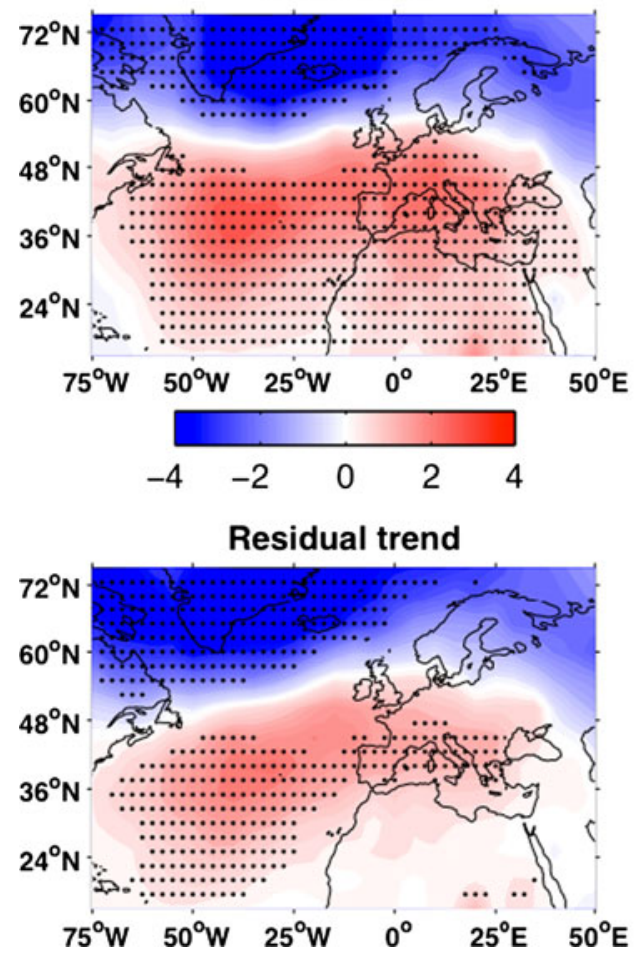

External trend

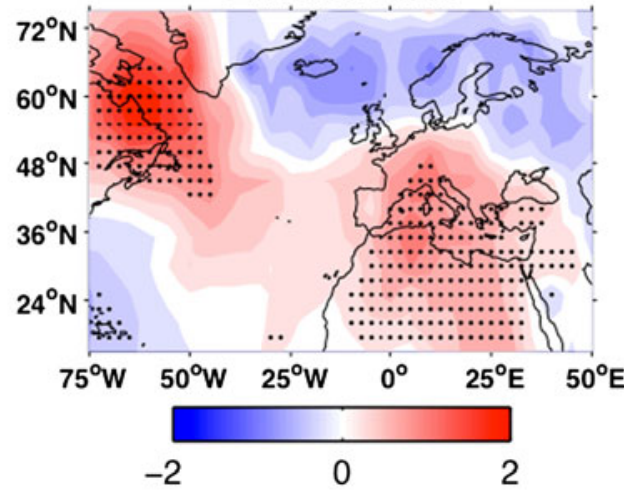

Multimodel mean trend

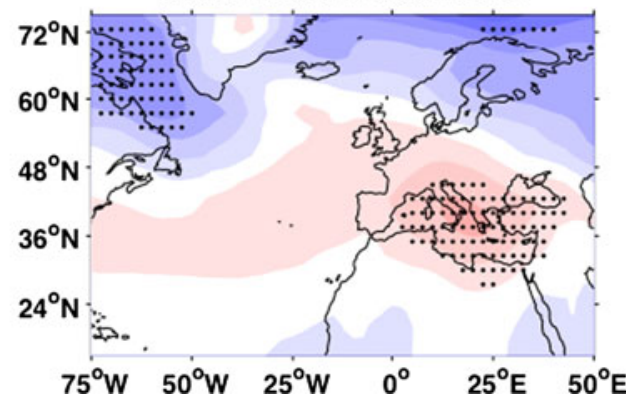

Total trend

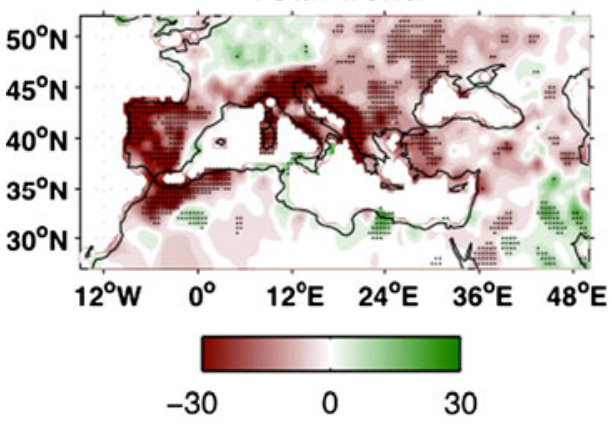

Residual trend

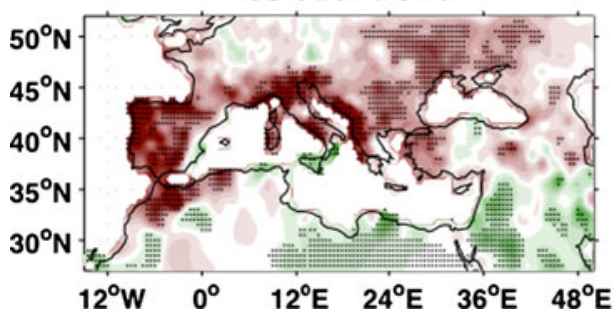

External trend

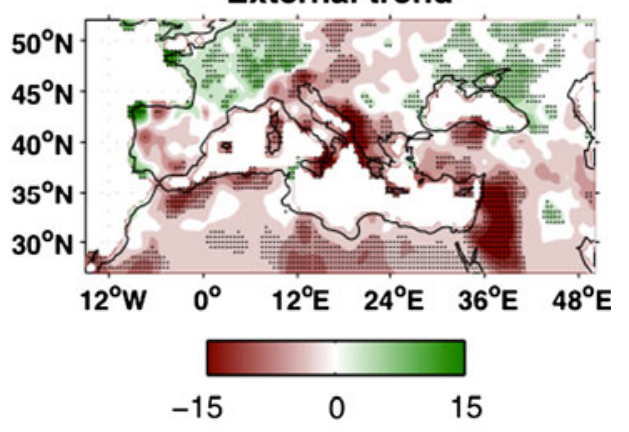

Multimodel mean trend

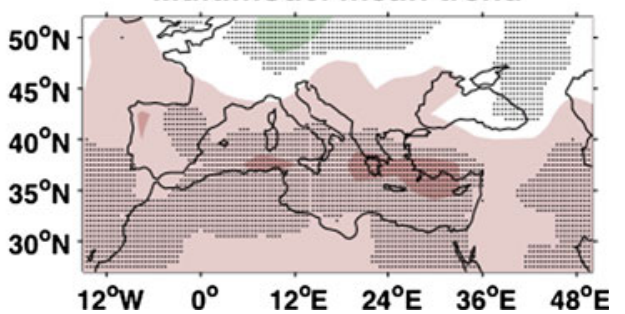

negative. As with the SLP, the difference between the externally forced trend using observations and the multimodel mean trend represents a range of possible amplitude for the observed trend resulting from external forcing.

To address the question of when the anthropogenically forced precipitation trend may approach the amplitude of the internal multi-decadal trend over the Mediterranean, we estimated the externally forced trend over the 21 st Century by extrapolating the estimated forced trend in the 20th Century into the 21st Century via linear regression, using the 21st Century signal time series together with the 20th Century regression coefficient as follows:

$\stackrel{*}{\operatorname{Pr}}(\mathrm{x}, \mathrm{y}, \mathrm{t})=\alpha(\mathrm{x}, \mathrm{y}) \operatorname{PC} 1(\mathrm{t})$

where $\alpha(\mathrm{x}, \mathrm{y})$ is the regression coefficient based on the 20th Century observations at each grid point, and PC1 is 


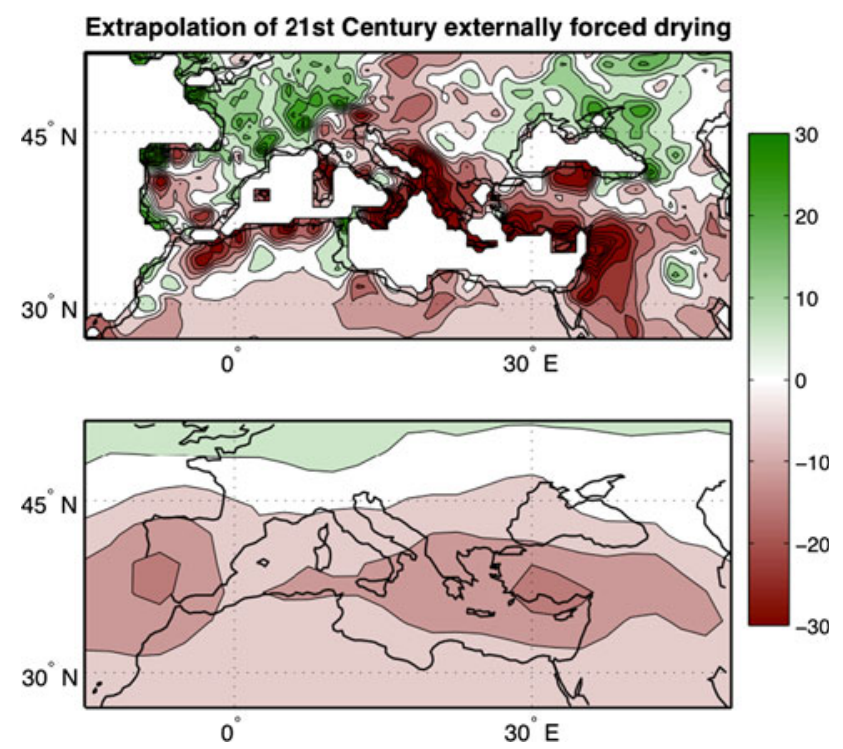

Fig. 9 Top: Extrapolation over the 21st century of the externallyforced Mediterranean precipitation trend, based on regression coefficients from the 20th century. In some locations the extrapolated drying exceeded the 20th century climatology and are shown as the climatology. Bottom: Multimodel mean trend for the 21st century. Units are mm/month per 100 years. Results are for the NovemberApril mean

the S/N EOF time series for the 21st Century. We then computed the 21 st Century linear trend in Pr*. The resulting pattern is shown in Fig. 9, along with the multimodel mean precipitation trend for the 21 st Century. The two patterns are substantially similar, but there are notable differences, particularly over the prominent topographical features surrounding the basin (a discrepancy that can be explained by the models' smooth topography) and in the Eastern Mediterranean. As with the 20th Century (Fig. 8, top and bottom right) the multimodel mean trend pattern as a whole is weaker than the externally forced portion of the observed trend. The two patterns in Fig. 9 can be used to represent an estimated range of externally forced 21 st Century drying. The extrapolated 21 st Century externally forced drying over much of the Mediterranean region is as strong or stronger than the total drying trend observed from 1960 to 2000, with the notable exception of the Iberian Peninsula where the external drying contribution is less, indicating that the future forced drying trend could, by the end of this century, approach the magnitude of the late 20th Century observed drying due to natural variability (see also Mariotti et al. 2008). (The extrapolated drying (top panel) exceeds the 20th Century climatological value in some locations. For this reason, rather than showing a decrease greater than the mean precipitation, the climatology is treated as a maximum of precipitation reduction and replaces the larger extrapolated values at those locations.)

\section{Conclusions}

Using 46 runs from 19 IPCC AR4 model simulations of the 20th Century we are able to show that the model simulations are capable of producing 30-year NAO and Mediterranean precipitation trends of magnitude comparable to those observed in the late 20th Century. The observed North Atlantic SLP and Mediterranean winter precipitation trends from 1965 to 1995 are within the overall estimated distributions of those simulated during the 20th Century by the models yet are outside the range defined by the lower and upper quartiles. However there is no systematic relation between the timing of the observed and model-simulated trends, which is consistent with both arising predominantly from internal variability. The models are able to produce trends of the magnitude of the observed NAO and associated precipitation trends from 1965 to 1995 as unusual events. Consistently, the tree ring NAO reconstruction also indicates that the strongest observed winter NAO trends during the 20th Century are unusual in the context of the last 600 years. However, it is also shown that the observed precipitation trend over this period is not entirely explained by the NAO trend since the drying is more widespread across the Mediterranean region than the typical NAO pattern which is concentrated in the western part of the basin.

The apparent ability of the models to simulate multidecadal NAO and associated Mediterranean precipitation trends, with the caveat that 100 years is not a very long record for characterizing multidecadal variability, allows us to use pre-industrial and 20th Century model simulations and signal-to-noise EOF maximization to determine relative contributions of natural variability and radiative forcing to 20th Century SLP and precipitation trends. The externally forced responses to SLP and precipitation are consistent and indicate strong positive NAO and drying trends that began in the late 20th Century and continue through the current century, becoming increasingly clear amidst the natural variability as the 21 st Century progresses. However, regressing the observed variability onto the timeseries of the forced responses shows that the externally forced components represent only modest fractions of the total NAO and Mediterranean rainfall trends for 1960-1999, and that the magnitude of the residual trends (taken to be internal variability) were several times larger. The magnitude of the spatial patterns of the NA SLP trend attributed to the external forcing and the multimodel mean trend in NA SLP are similar, implying that the signal-to-noise based estimate is realistic. The accumulation of evidence therefore suggests that the external radiative forcing and the internal variability combined from the 1960s to the 1990s to produce a strongly positive SLP trend and robust drying in the Mediterranean, but that the 
multidecadal natural variability dominated the contribution from the external forcing. This is consistent with Osborn (2004) who stated that the observed NAO trend could be explained by a combination of a radiatively forced trend with a stronger trend arising from natural variability. Importantly the drying in the Middle East does, however, arise from the external forcing since the positive NAOassociated trend would have contributed moistening here. On the other hand, the very strong observed drying on the Iberian peninsula was primarily caused by the NAO trend with the trend caused by external forcing much weaker. These results are true only to the extent that the methodologies used here, based on both the individual models and the multimodel mean, are able to provide realistic estimates of the forced signal. However, according to our best estimate of the external radiatively forced responses we should expect their contribution to trends to grow relative to the internal variability through the 21 st Century. Based on the linear increase in the signal projected by this model-based estimate under the A1B emissions scenario, the forced precipitation change could begin to approach the magnitude of observed multidecadal natural variability by the end of the 21st Century establishing the level of aridity seen in the late 20th Century as the new climate. However if the strength of the natural variability observed in the 20th Century (which could also change in the future) persists, then the path towards this drier climate might not be smooth but involve drier and wetter periods of varying length around a steadily drying mean climate. Decreasing precipitation, as well as increasing Mediterranean Sea evaporation and salinity, could have profound consequences with respect to the Mediterranean water cycle (Mariotti 2010) by the end of the 21st Century, highlighting the importance of more research and better understanding of Mediterranean hydroclimate variability and change.

Acknowledgments The authors would like to thank the reviewers for their detailed and constructive comments, the Global Decadal Hydroclimate group at Lamont and Columbia for their input, and NOAA and NSF for support. This work is supported under the following grants: NSF AGS-1128172, NA10OAR4310137, NSF ATM08-04107, NSF AGS 05-43256 and NOAA NA08OAR4320912.

\section{References}

Allan R, Ansell T (2006) A new globally complete monthly historical gridded mean sea level pressure dataset (HadSLP2): 1850-2004. J Climate 19(22):5816-5842

Allen MR, Smith LA (1997) Optimal filtering in singular spectrum analysis. Phys Lett A 234(6):419-428

Barnston AG, Livezey RE (1987) Classification, Seasonality and Persistence of Low-Frequency Atmospheric Circulation Patterns. Mon Weather Rev 115(6):1083-1126

Chang P, Saravanan R, Ji L, Hegerl GC (2000) The effect of local sea surface temperatures on atmospheric circulation over the tropical Atlantic sector. J Climate 13(13):2195-2216
Cook E, D'Arrigo R, Mann M (2002) A Well-Verified, Multiproxy Reconstruction of the Winter North Atlantic Oscillation Index since A.D. 1400. J Climate 15:1754-1764

Cullen HM, de Menocal PB (2000) North Atlantic influence on Tigris-Euphrates streamflow. Int J Clim 20(8):853-863

Deser C, Phillips A, Bourdette V, Teng H (2011) Uncertainty in climate change projections: the role of internal variability. Climate Dyn. doi:10.1007/s00382-010-0977-x

Dunkeloh A, Jacobeit J (2003) Circulation dynamics of Mediterranean precipitation variability 1948-98. Int J Clim 23(15):1843-1866

Feldstein SB (2002) The recent trend and variance increase of the annular mode. J Climate 15(1):88-94

Gillett N, Graf H, Osborn T (2003) Climate change and the north Atlantic oscillation. The north Atlantic oscillation: climatic significance and environmental impact. e. a. JW Hurrell, Geophys Mono, 134

Held IM, Soden BJ (2006) Robust responses of the hydrological cycle to global warming. J Climate 19(21):5686-5699

Hoerling MP, Hurrell JW, Xu TY (2001) Tropical origins for recent North Atlantic climate change. Science 292(5514):90-92

Hurrell JW (1995) Decadal trends in the north-atlantic oscillation regional temperatures and precipitation. Science 269(5224): 676-679

Hurrell JW, Kushnir Y, Ottersen G, Visbeck M (2003) An overview of the North Atlantic Oscillation. The North Atlantic Oscillation: climatic significance and environmental impact. e. a. JW Hurrell. Geophys Mono 134:1-35

Hurrell JW, Visbeck M, Busalacchi A, Clarke RA, Delworth TL, Dickson RR, Johns WE, Koltermann KP, Kushnir Y, Marshall D, Mauritzen C, McCartney MS, Piola A, Reason C, Reverdin G, Schott F, Sutton R, Wainer I, Wright D (2006) Atlantic climate variability and predictability: A CLIVAR perspective. J Climate 19(20):5100-5121

Kushnir Y, Robinson WA, Chang P, Robertson AW (2006) The physical basis for predicting Atlantic sector seasonal-to-interannual climate variability. J Climate 19(23):5949-5970

Lu J, Vecchi GA, Reichler TA (2007) Expansion of the Hadley cell under global warming. Geophys Res Lett, 34(6). doi:10.1029/ 2006GL028443

Mariotti A (2010) Recent changes in ghe mediterranean water cycle: a pathway toward long-term regional hydroclimatic change? J Climate 23(6):1513-1525. doi:10.1175/2009JCLI3251.1

Mariotti A, Dell'Aquila A (2011) Decadal climate variability in the Mediterranean region: roles of large-scale forcings and regional processes. Climate Dyn. doi:10.1007/s00382-011-1056-7

Mariotti A, Zeng N, Yoon J, Artale V, Navarra A, Alpert P, Li L (2008) Mediterranean water cycle changes: transition to drier 21 st century conditions in observations and CMIP3 simulations. Environ Res Lett 3(4). doi:10.1088/1748-9326/3/4/044001

Meehl GA, Covey C, Delworth T, Latif M, McAvaney B, Mitchell JFB, Stouffer RJ, Taylor KE (2007) The WCRP CMIP3 multimodel dataset-a new era in climate change research. B Am Meteorol Soc 88(9):1383-1394

Nakicenovic N, Swart R (2000) Special report on emissions scenarios. Cambridge University Press, Cambridge

Osborn TJ (2004) Simulating the winter North Atlantic Oscillation: the roles of internal variability and greenhouse gas forcing. Climate Dyn 22(6-7):605-623

Osborn TJ, Briffa KR, Tett SFB, Jones PD, Trigo RM (1999) Evaluation of the North Atlantic Oscillation as simulated by a coupled climate model. Climate Dyn 15(9):685-702

Previdi M, Liepert BG (2007) Annular modes and Hadley cell expansion under global warming. Geophys Res Lett 34(22). doi:10.1029/2007GL031243

Schneider EK, Bengtsson L, Hu ZZ (2003) Forcing of Northern Hemisphere climate trends. J Atmos Sci 60(12):1504-1521 
Schneider U, Fuchs T, Meyer-Christoffer A, Rudolf B (2008) Global precipitation analysis products of the GPCC. Global Precipitation Climatology Centre (GPCC), DWD, Internet publication: 1-12

Seager R, Ting MF, Held I, Kushir Y, Lu J, Vecchi G, Huang H, Harnik N, Leetma A, Lau N, Li C, Velez J, Naik N (2007) Model projections of an imminent transition to a more arid climate in southwestern North America. Science 316(5828):1181-1184

Seager R, Naik N, Vecchi GA (2010) Thermodynamic and dynamic mechanisms for large-scale changes in the hydrological cycle in response to global warming. J Climate 23(17):4651-4668

Shindell DT, Miller RL, Schmidt GA, Pandolfo L (1999) Simulation of recent northern winter climate trends by greenhouse-gas forcing. Nature 399(6735):452-455

Solomon S, Qin D, Manning M, Chen Z, Marquis M, Averyt KB, Tignor M, Miller HL (eds.) (2007): IPCC, 2007: climate change 2007: the physical science basis. Contribution of working group I to the fourth assessment report of the intergovernmental panel on climate change

Thompson DWJ, Wallace JM, Hegerl GC (2000) Annular modes in the extratropical circulation. Part II: Trends. J Climate 13(5):1018-1036
Thompson DWJ, Lee S, Baldwin MP (2003) Atmospheric processes governing the Northern Hempisphere Annular Mode/North Atlantic Oscillation. The North Atlantic Oscillation: climatic significance and environmental impact. e. a. J.W. Hurrell. Geophys Mono 134:81-112

Ting MF, Kushnir Y, Seager R, Li CH (2009) Forced and Internal Twentieth-Century SST Trends in the North Atlantic. J Climate 22(6): 1469-1481

Venzke S, Allen MR, Sutton RT, Rowell DP (1999) The atmospheric response over the North Atlantic to decadal changes in sea surface temperature. J Climate 12(8):2562-2584

Wu Y, Ting MF, Seager R, Huang H, Cane M (2010) Changes in storm tracks and energy transports in a warmer climate simulated by the GFDL CM2.1 model. Climate Dyn. doi:10.1007/ s00382-010-0776-4

Yin JH (2005) A consistent poleward shift of the storm tracks in simulations of 21st century climate. Geophys Res Lett 32(18) 